\title{
Emerging strategies in the treatment of poststroke depression and psychiatric distress in patients
}

This article was published in the following Dove Press journal:

Psychology Research and Behavior Management

3 December 2010

Number of times this article has been viewed

\author{
Vincent F Capaldi II' \\ Gary HWynn² \\ 'Department of Psychiatry, \\ Walter Reed Army Medical \\ Center, Washington, DC, USA; \\ ${ }^{2}$ Department of Military Psychiatry, \\ Center for Military Psychiatry and \\ Neuroscience, Walter Reed Army \\ Institute of Research, Silver Spring, \\ MD, USA
}

Correspondence: Vincent F Capaldi II Department of Psychiatry, Walter Reed Army Medical Center, 6900 Georgia Ave., Washington, DC 20307-500I, USA

Tel + I 202782 I774

Fax + I 2027825183

Email vin@capaldi.org

\begin{abstract}
Poststroke depression (PSD) is a common sequela of stroke associated with increased morbidity and mortality among stroke survivors. PSD has been associated with poorer rehabilitative outcomes, longer inpatient stays, inefficient use of medical resources, worsened cognitive decline, and increased suicidality. This article reviews the definition and proposed etiology of PSD as well as current and emerging evidence-based prevention, screening, and treatment modalities. The timely use of prevention and treatment techniques including pharmacologic and nonpharmacologic methods may improve treatment outcomes and enhance the quality of life in stroke patients.
\end{abstract}

Keywords: poststroke depression, SSRI, TCA, stroke, CBT

\section{Introduction}

According to a 2008 World Health Organization (WHO) report, stroke and other cerebrovascular diseases were the second leading cause of death in 2004, resulting in more than 5.7 million deaths and accounting for roughly $10 \%$ of deaths worldwide. ${ }^{1}$ Individuals who survive this potentially deadly event are often left with significant physiologic and psychiatric complications. The psychiatric sequelae of stroke and cerebrovascular disease include maladies such as anxiety, ${ }^{2}$ psychosis, posttraumatic stress disorder (PTSD), ${ }^{3}$ and poststroke depression (PSD). ${ }^{4}$ More specifically, PSD has been reported to have a prevalence of $25 \%-80 \%$ in stroke victims depending on the study instrument. ${ }^{5-8}$ In this article, we provide an up-to-date review of the etiology, diagnosis, treatment, and impact of PSD.

For an individual, the sequelae of stroke can be life-altering. A previously independent person may now require others to perform the most basic of daily activities. Others may find themselves unable to perform their jobs or participate in their usual social activities. This significant loss of function can result in profound and debilitating depression. Additionally, research has shown that depression compounds the disabling effects of a stroke, ${ }^{9-12}$ worsens cognitive decline, ${ }^{13,14}$ and increases suicidality as well as overall morbidity and mortality. ${ }^{15-17}$

For society, the costs associated with PSD are tremendous. PSD is associated with poorer rehabilitative outcomes, ${ }^{18}$ longer inpatient rehabilitation stays, increased inpatient and outpatient medical utilization, ${ }^{19,20}$ and inefficient use of rehabilitation services. ${ }^{21}$ The toll of caring for individuals with PSD significantly impacts the community at large, but is felt most acutely by those providing the day-to-day care of stroke survivors. Many caregivers experience provider fatigue, social isolation, and mood symptoms. ${ }^{22-24}$ These widespread 
costs to the survivor, their caregivers, and the community at large show the need for further research in this area and aggressive multidisciplinary treatment inclusive of all affected.

\section{Defining PSD}

A very wide range of PSD prevalence estimates exist in the current literature. This variability stems from the difficulty in assessment and diagnosis of depression in stroke survivors. Currently, there is no standardized, widely accepted measure of PSD. The heterogeneity of cognitive and functional deficits in stroke survivors makes standardized measures difficult. Prevalence estimates in this population may be over- or underdiagnosing this disorder due to the difficulty in distinguishing depressive symptoms from stroke sequelae. ${ }^{25}$ The most appropriate means of diagnosing PSD have remained uncertain since the midtwentieth century when it was first understood as a significant complication of stroke. The heterogeneous symptoms comprising PSD have been a continual source of controversy in field of geriatric psychiatry given a lack of consensus on etiology, pathogenesis, and course in stroke survivors. ${ }^{26}$

There are four methodological approaches to the diagnosis of PSD: ${ }^{27}$ the inclusive approach, ${ }^{28}$ the etiologic approach, ${ }^{29}$ the substitutive approach, ${ }^{30}$ and the exclusive approach. ${ }^{31}$ Under the inclusive approach, all depressive symptoms would be considered at face value regardless of underlying pathogenesis. ${ }^{28}$ Critics of this approach point to overdiagnosis of depression in patients where neurovegetative symptoms are better categorized as stroke symptoms. The etiologic approach would count depressive symptoms only if the clinician believes the symptom is related to organic depression and not stroke-related deficits. ${ }^{29}$ The substitutive approach uses other psychological symptoms of depression in place of neurovegetative symptoms. ${ }^{30}$ Under this paradigm, neurovegetative symptoms are excluded because of the confounding vegetative symptoms associated with stroke. Finally, the exclusive approach only includes symptoms more prevalent in depressed versus nondepressed stroke survivors. ${ }^{31}$

\section{Etiology of PSD}

As is the case with nonstroke-related depression, the two primary sources of pathology in the development of PSD are biological and psychosocial. In the following section, we explore the evidence supporting both the biologic and psychosocial causes of this disorder.

\section{Biological evidence}

One would not be reading this article were it not for the strong association between the decidedly biologic phenomenon of stroke and the development of depression. Alexopoulos et $\mathrm{al}^{32}$ outlined the following four areas of clinical evidence supporting the biologic hypothesis of PSD: 1) the increased prevalence of depression in patients with hypertension, diabetes, and coronary artery disease, ${ }^{33-35} 2$ ) the increased prevalence of depression among patients after stroke, ${ }^{36,37} 3$ ) the strong association of late-onset depression and the increased frequency of silent stroke and white matter hyperintensities, ${ }^{38-41}$ and 4) the rare association of family history of mood disorders in the context of silent stroke. ${ }^{42}$

The development of depression is more likely after stroke compared to any other physical disability. ${ }^{43}$ Researchers since the 1970s have proposed various mechanisms by which ischemic insult to certain areas of the brain results in depressed mood. ${ }^{44-47}$ Early hypotheses posit that ischemic insults to neural circuits of mood regulation, specifically left frontal subcortical circuits, result in depletion of biogenic amines and contribute to symptoms of depression. ${ }^{48,49}$ The association between ischemic lesions in the frontal lobe and depression is strongest early in the poststroke period, but this association appears to wane over time. ${ }^{46}$ Perhaps, this temporal association represents adjustment disorder with depressed mood in the early phase of recovery that resolves after the patient regains some level of function.

Some authors have suggested that the significant physical disability associated with stroke likely contributes to depressive symptoms in poststroke patients. However, early research found no significant difference in the severity of depression between groups of elderly patients with chronic disability due to stroke and a matched control group with extracerebral disorders. ${ }^{50}$ Subsequently, research has shown PSD to develop even in patients with anosognosia. ${ }^{51,52}$ Patients with anosognosia are unaware of physical deficits associated with their stroke yet exhibit depressive symptoms similar to patients with equivalent levels of disability. Even in the absence of disability, patients with ischemic insults to striatofrontal circuits demonstrate higher rates of depression compared to patients with 'silent' infarcts. ${ }^{32,38,40}$ This evidence supports the model of PSD as having at least an aspect that is primarily biologic despite early research to the contrary.

\section{Psychosocial evidence}

Multiple studies have attempted to localize a lesion consistent with PSD, but recent literature does not support discrete localized ischemia as the sole cause of depressive symptoms. ${ }^{53,54}$ The severity of depression and the prevalence of depressive symptoms after stroke have been found to be comparable to other illnesses with equivalent levels of disability. ${ }^{6,55}$ In fact, 
a systematic review by Carson et al found no increased risk of depression after stroke based on the location of a brain lesion over time. ${ }^{53}$ This evidence contradicts the evidence presented demonstrating an association between frontal lesions and the development of early depression. Studies differ in conclusions based on when subjects are sampled for symptoms. Although earlier symptoms have been associated with localization of brain lesions, subjects sampled more than 1 year after stroke show no such association.

Similar to nonstroke-related depression, one is able to predict the development of PSD using a number of psychosocial factors. ${ }^{56,57}$ Kendler found that stressful life events, genetic factors, a previous history of major depressive disorder (MDD), and neuroticism contributed equally to the development of depression in stroke and nonstroke patients. ${ }^{56}$ Functional disability after stroke appears to be the strongest risk factor for developing PSD. More than 15 articles found disability to be the strongest predictor of PSD, ${ }^{55,58,59}$ while just as many studies failed to find this association. ${ }^{58,60}$ Singh et al found that an important predictor of the development of PSD immediately poststroke was localization of the lesion while at 3 months severity of disability became significantly more predictive than lesion location. ${ }^{61}$

If the etiology of PSD were purely biological, resulting from brain lesions secondary to stroke, the development of PSD should not be influenced by prior psychiatric history or life experience, yet clinical studies have indeed found these factors to be important in the development of PSD. According to Whyte and Mulsant, 8 of 14 studies showed past psychiatric history to be a risk factor in the development of PSD. ${ }^{58}$ Family history has also been shown to be a risk factor in the development of PSD. ${ }^{62-65}$ Further evidence indicates that personality disorders, social isolation, and poor familial support predispose individuals to developing depression after stroke. ${ }^{59,63,64,66,67}$ Proponents of the biologic hypothesis of PSD suggest that evidence of past psychiatric history, family history, and premorbid-functioning-associated risk does not necessarily contradict the biologic underpinnings of this disorder but serve as markers of susceptibility to a uniquely biologic process.

As can be seen from the preceding discussion, the data in this area are voluminous, contradictory, and indecisive regarding the degree to which biologic and psychological factors contribute to the development of PSD. On the basis of this evidence, PSD is most likely a multifactorial disorder. Minimizing or marginalizing the significant psychological stress and trauma associated with the acute development of disability associated with stroke would be ill advised, while the evidence indicates that particular lesion locations are strongly associated with the development of PSD in the early poststroke period. Like many other diseases involving the brain, this disorder might be best characterized by the stress-diathesis model or the two-hit hypothesis where a genetic or psychological predisposition to depression confers an increased susceptibility to the biological and psychiatric sequela of stroke. The degree to which these biological and psychological factors confer increased risk to an individual remains poorly understood.

\section{Prevention and diagnosis}

Prevention of PSD begins with the prevention of stroke. Annually, in the United States, approximately 610,000 people suffer stroke for the first time. ${ }^{68}$ Major modifiable risk factors for stroke include hypertension, diabetes, cigarette smoking, and hyperlipidemia. ${ }^{69}$ Despite widespread acknowledgment of these risk factors, stroke remains the third leading cause of death in the United States. ${ }^{6}{ }^{2}$ Primary care physicians and mental health providers should be vigilant in monitoring blood pressure, cholesterol, and glucose control while encouraging smoking cessation. Family history is vitally important to properly assess the risk factors for stroke and depression. A family history of early-onset stroke or depression should result in earlier and more aggressive prevention strategies.

At the present time, there is little evidence to support the prophylactic treatment of stroke patients with antidepressant medications. In a review of 14 clinical trials, pharmacotherapy showed no clear effect in preventing PSD, but psychotherapy did show a statistically significant, though small, effect. ${ }^{70}$ To date, only one study has shown a significant benefit using an antidepressant (sertraline) as a prophylaxis against PSD. This study was a double-blind, placebo-controlled study of 155 patients over a 12 -month period, and it showed $10 \%$ PSD in the treatment group and $30 \%$ in the placebo group. ${ }^{71}$ The appropriate mechanisms for prevention remain unclear but given the limited downside to psychotherapy, such an approach seems a safe and appropriate course until further research is concluded.

Patients who suffer a stroke should be screened for symptoms of depression throughout their poststroke course. There is little consensus regarding the exact timing of PSD screening given the inherent heterogeneity of the disease etiology. Further complicating matters is the natural interindividual variability of stroke survivors. Despite this variability, there are some general principles evident in the current literature. In 2002, Whyte and Mulsant reviewed the prevalence of MDD after stroke based on the time since stroke. ${ }^{58}$ Peak in 
symptoms occurred approximately 3-6 months after stroke with a subsequent $50 \%$ decline in prevalence by 1 year. ${ }^{58}$ This finding suggests that screening should occur more frequently (eg, monthly) in the initial poststroke period and should continue at regular intervals (eg, annually) for any stroke survivor.

Several risk factors for PSD also appear to be strongly correlated to PSD symptom severity. These risk factors include the discrepancy between premorbid and poststroke physical functioning, ${ }^{72}$ a history of a psychiatric condition (eg, depression), ${ }^{63}$ female sex, ${ }^{61,64}$ location of CVA lesion, ${ }^{73}$ and reversal of social roles. ${ }^{74}$ Cognitive impairment secondary to stroke ${ }^{14,59}$ and communication difficulties due to aphasia also contribute to increased rate of PSD in elderly populations. ${ }^{14,75}$ Patients with limited social supports also have higher rates of depression after stroke. ${ }^{6,74}$ These risk factors coupled with a biologic predisposition to depression based on a family history increase the likelihood of disease development. Screening and evaluations for PSD should include these factors at a minimum in order to assess the likelihood of the disorder and the potential severity of symptoms. Individuals with either numerous risk factors for developing PSD and/or factors indicating a more severe case of PSD need increased monitoring, preferably by experienced professionals.

In addition to a careful history and evaluation of PSD risk factors, psychometric tests may also be useful in assessment and monitoring. As indicated in the preceding section entitled, 'defining PSD,' the way one defines PSD determines the measures employed to diagnose the illness. Gianotti et al designed the poststroke depression rating scale (PS-DRS) in order to examine the phenomenology of PSD. ${ }^{76,77}$ This measure was developed to assess emotional, affective, and vegetative defects after stroke. Table 1 provides a list of items included in the PS-DRS. Their results demonstrated a high correlation between depression and disability but did not validate the addition of apathy, hyperemotionalism,

Table I Items included in the post stroke depression rating scale (PS-DRS)

Depressed mood
Guilt feelings
Thoughts of death or suicide
Vegetative symptoms
Apathy and loss of interest
Anxiety
Catastrophic reaction
Hyperemotionalism
Anhedonia
Diurnal mood variations

and catastrophic reactions in determining the presence or absence of PSD.

There have been several measures validated for screening of major depressive symptoms (DSM-IV criteria) in stroke patients. The Beck depression inventory (BDI), hospital anxiety and depression scale (HADS), SCL-90, and Hamilton depression rating scale (HDRS) have all been validated in poststroke patients with good sensitivity and specificity. ${ }^{78}$ In a recent study by Healey et al the brief assessment schedule depression cards (BASDEC) were found to be the most accurate screening tools for PSD compared to the HADS and BDI (fast screen). ${ }^{79}$ Using the BASDEC will result in less false positives and more efficient screening and treatment of PSD patients.

All tests may not be valid for a given individual based on poststroke cognitive disability and language deficits. Researchers have developed assessments to adapt to the cognitive deficits suffered by many stroke survivors. Gordon and Hibbard developed the structured assessment of depression in brain-damaged individuals (SADBD). ${ }^{5}$ This assessment only requires yes or no answers from participants and also includes visual cue cards for patients with aphasiac symptoms. In general, this diagnostic tool has not been widely adopted because of a lack of a graded response or suitability in patients with severe comprehension difficulties. Other researchers have developed measures that have been shown to be valid to detect depressive symptoms in aphasic stroke patients, namely, the stroke aphasic depression questionnaire (SADQ-10). ${ }^{80}$ It is important for providers to assess deficits in patients prior to administering screening questionnaires to ensure the validity of the test.

Once a patient is identified with depressive symptoms, there are few reliable predictors of treatment outcomes. Onset of depressive symptoms after stroke appears to be predictive of PSD duration and treatment outcome. Stroke survivors who develop depressive symptoms within hours after stroke have a better prognosis for resolution of depressive symptoms within 1 year of onset. ${ }^{81,82}$ However, approximately $30 \%$ of patients develop PSD up to 6 months after stroke. ${ }^{83}$ Among patients who have delayed onset of depressive symptoms, Anderson et al found that patients developing depression 7 weeks after stroke had lower rates of spontaneous recovery. ${ }^{84}$

Prevention of disease should be the highest priority for physicians; however, when stroke occurs, providers should be vigilant for symptoms of depression. Although psychometric tools are helpful in the diagnosis and treatment of PSD symptoms, a thorough history of premorbid risk factors is absolutely essential for guiding diagnosis and choosing the 
most appropriate treatment modality. The timing of onset of PSD symptoms after stroke may indicate which patients are refractory to typical treatment as outlined in the following section.

\section{Treatment of PSD}

\section{To treat or not to treat}

Several reviews of this topic indicate that a large portion of providers are uncomfortable with prescribing an antidepressant, antipsychotic, or stimulant to an elderly patient after stroke. ${ }^{85}$ Conservative management of these patients is certainly not without merit. Many of these patients are on multiple medications, and the addition of yet another medication may have an unforeseen consequence such as a drug interaction. Additionally, there is an increased risk of bleeding associated with selective serotonin reuptake inhibitor (SSRI) and an increased risk of stroke associated with the long-term use of atypical antipsychotics. ${ }^{86}$ These risks should be carefully considered prior to prescribing such medications.

Some providers consider depression as a natural byproduct of significant physical disability after stroke that will eventually resolve over time as the patient adapts to his or her new disability. Research has shown, however, that the use of antidepressants can result in significant improvement of symptoms regardless of the physical disability. In a recent review of more than 50 studies, antidepressant medications were shown to be more effective than placebo for treatment of depressive symptoms in poststroke patients. ${ }^{87}$ Improvement of depressive symptoms will generally result in improved functional recovery and rehabilitative outcomes. ${ }^{88}$ This evidence suggests that despite the potential risks, consideration should be given to pharmacotherapeutic interventions in PSD (Table 2).

\section{Tricyclic antidepressant therapy}

Tricyclic antidepressants (TCAs) have been shown to be efficacious in the treatment of PSD (Table 3). In 2000,

Table 2 Current evidence-based treatments for post stroke depression

\begin{tabular}{ll}
\hline Intervention & Level of recommendation \\
\hline $\begin{array}{l}\text { Selective serotonin } \\
\text { reuptake inhibitors }\end{array}$ & Moderate evidence of utility \\
Tricyclic antidepressants & Moderate evidence of utility \\
Atypical antipsychotics & Evidence is lacking to make \\
& recommendation \\
Mood stabilizers & Evidence is lacking to make \\
& recommendation \\
Stimulant medications & Moderate evidence of utility \\
Cognitive behavioral therapy & Likely small net benefit \\
\hline
\end{tabular}

a double-blind, randomized, placebo-controlled trial by Robinson et al demonstrated a significant decrease in Hamilton depression scale (HAM-D) scores in patients treated with nortriptyline for 12 weeks compared to fluoxetine and placebo treatment groups. ${ }^{89,90}$ Additionally, patients treated with nortriptyline showed a decrease in anxiety symptoms and improved recovery of activities of daily living. ${ }^{89}$

There is little doubt that TCAs are effective in the treatment of depressive symptoms; however, these drugs confer a therapeutic benefit as well as a significant clinical risk of side effects. Alpha-1-adrenergic blockade by TCAs may result in orthostatic hypotension, making patients prone to falls and thus intracranial hemorrhage. The affinity of TCAs for histaminergic receptors causes increased sedation which may decrease intellectual functioning - a poorly tolerated side effect in poststroke patients. Anticholinergic side effects of TCAs include urinary retention, dry mouth, and constipation. TCAs are also a type 1a antiarrhythmic which can result in QT prolongation and torsades de pointe. Stroke patients with likely coronary artery disease may be particularly susceptible to the arrhythmogenic effects of TCAs. These side effects are the primary reason that TCAs see limited use in both general practice and in the treatment of PSD.

\section{SSRI therapy}

The efficacy of a number of SSRIs for PSD have been studied over the past few decades. Most SSRIs have demonstrated minimal efficacy in the treatment of PSD, supporting the hypothesis of PSD as uniquely different from MDD. In five double-blind, placebo-controlled studies, sertraline and fluoxetine were no better than placebo in treatment or prevention of PSD. ${ }^{71,91-94}$ The lengths of these studies are significant limitations as most only lasted for 12 weeks, possibly not providing enough time to observe a significant change in subjects. It is also important to note that while some studies show no improvement of poststroke depressive symptoms, many studies demonstrate functional improvement with the use of SSRI medications. ${ }^{88,95}$ Fruewald et al followed patients for additional time (18 months) and found improvements in depressive symptoms among those in the fluoxetine group with significant dropout in the placebo group. ${ }^{92}$ Of the SSRIs studied in the treatment of PSD, citalopram has shown the most benefit as demonstrated by symptom reduction on the BDI scale. ${ }^{84,96}$ Despite the mixed evidence regarding the efficacy of SSRIs in the treatment of PSD, they remain the recommended first-line pharmacotherapy for PSD given favorable side effect profile. ${ }^{97}$ Suggested treatment guidelines for PSD acknowledge there is no evidence to suggest that SSRIs improve PSD 
Table 3 Trials for the treatment of post stroke depression

\begin{tabular}{|c|c|c|c|c|c|c|c|c|c|}
\hline $\begin{array}{l}\text { Treatment } \\
\text { studied }\end{array}$ & Author & $\begin{array}{l}\text { Type of } \\
\text { trial }\end{array}$ & $\mathbf{N}$ & $\begin{array}{l}\text { Diagnostic } \\
\text { criteria }\end{array}$ & $\begin{array}{l}\text { Outcome } \\
\text { measure }\end{array}$ & $\begin{array}{l}\text { Trial length } \\
\text { (weeks) }\end{array}$ & $\begin{array}{l}\text { Time from stroke } \\
\text { (months) }\end{array}$ & $\begin{array}{l}\text { Treatment } \\
\text { response }\end{array}$ & Placebo \\
\hline \multirow[t]{2}{*}{ Nortriptyline } & $\begin{array}{l}\text { Lipsey } \\
\text { et a }\left.\right|^{90}\end{array}$ & $\mathrm{RCT}$ & 34 & $\begin{array}{l}\text { DSM III } \\
\text { Major } \\
\text { Minor }\end{array}$ & $\begin{array}{l}\text { HDRS } \\
\text { ZSRDS }\end{array}$ & $4-6$ & $<18$ & $36 \%^{+}$ & $22 \%^{\dagger}$ \\
\hline & $\begin{array}{l}\text { Robinson } \\
\text { et } \mathrm{a}^{89}\end{array}$ & $\mathrm{RCT}$ & 56 & $\begin{array}{l}\text { DSM IV } \\
\text { Major } \\
\text { Minor }\end{array}$ & HDRS & 12 & $<6$ & $63 \%^{\ddagger}$ & $23 \% \%^{\ddagger}$ \\
\hline \multirow[t]{4}{*}{ Fluoxetine } & $\begin{array}{l}\text { Robinson } \\
\text { et } \mathrm{a}^{89}\end{array}$ & $\mathrm{RCT}$ & 56 & $\begin{array}{l}\text { DSM IV } \\
\text { Major } \\
\text { Minor }\end{array}$ & HDRS & 12 & $<6$ & $9 \%$ & $23 \%$ \\
\hline & $\begin{array}{l}\text { Wiart } \\
\text { et al }{ }^{112}\end{array}$ & RCT & 66 & $\begin{array}{l}\text { ICD-I0 } \\
\text { Major }\end{array}$ & MADRS & 6 & $<6$ & $63 \%^{\ddagger}$ & $33 \%^{\ddagger}$ \\
\hline & $\begin{array}{l}\text { Fruehwald } \\
\text { et } \mathrm{al}^{92}\end{array}$ & $\mathrm{RCT}$ & 54 & $\begin{array}{l}\text { DSM IV } \\
\text { Major } \\
\text { Minor }\end{array}$ & $\begin{array}{l}\text { HDRS } \\
\text { BDI }\end{array}$ & $\begin{array}{l}16 \\
72\end{array}$ & $<1$ & $\begin{array}{l}69.2 \% \\
81.8 \% *\end{array}$ & $\begin{array}{l}75 \% \\
27.8 \% *\end{array}$ \\
\hline & $\begin{array}{l}\text { Choi-Kwon } \\
\text { et } \mathrm{al}^{93}\end{array}$ & $\mathrm{RCT}$ & 152 & $\begin{array}{l}\text { DSM IV } \\
\text { Major } \\
\text { Minor }\end{array}$ & $\begin{array}{l}\text { BDI } \\
\text { Clinical } \\
\text { STAS }\end{array}$ & $\begin{array}{l}16 \\
26\end{array}$ & 14 & $\begin{array}{l}28.7 \% \\
27.1 \%\end{array}$ & $\begin{array}{l}15.5 \% \\
14.7 \%\end{array}$ \\
\hline Sertraline & $\begin{array}{l}\text { Murray } \\
\text { et } \mathrm{al}^{91}\end{array}$ & $\mathrm{RCT}$ & 123 & $\begin{array}{l}\text { DSM IV } \\
\text { Major } \\
\text { Minor }\end{array}$ & $\begin{array}{l}\text { MADRS } \\
\text { EDS }\end{array}$ & 26 & $\mathrm{I}-52$ & $33.9 \%$ & $42.6 \%$ \\
\hline Citalopram & $\begin{array}{l}\text { Andersen } \\
\text { et } \mathrm{al}^{84}\end{array}$ & $\mathrm{RCT}$ & 66 & $\begin{array}{l}\text { DSM III } \\
\text { Major } \\
\text { Minor }\end{array}$ & $\begin{array}{l}\text { HDRS } \\
\text { MES }\end{array}$ & 16 & 4 & $65 \%^{+}$ & $15 \%^{\dagger}$ \\
\hline Methylphenidate & $\begin{array}{l}\text { Grade } \\
\text { et al }{ }^{101}\end{array}$ & $\mathrm{RCT}$ & 22 & $\begin{array}{l}\text { DSM IV } \\
\text { Major } \\
\text { Minor }\end{array}$ & $\begin{array}{l}\text { HDRS } \\
\text { ZSRDS }\end{array}$ & 3 & $<1$ & $28 \% \%^{\ddagger}$ & $24 \%^{\ddagger}$ \\
\hline $\begin{array}{l}\text { Cognitive } \\
\text { behavioral } \\
\text { therapy }\end{array}$ & $\begin{array}{l}\text { Lincoln } \\
\text { et } \text { al }^{106}\end{array}$ & $\begin{array}{l}\text { Case } \\
\text { series }\end{array}$ & 19 & $\begin{array}{l}\text { DSM IV } \\
\text { Major } \\
\text { Minor }\end{array}$ & $\begin{array}{l}\text { BDI } \\
\text { HADS }\end{array}$ & 16 & $<1$ & $24 \%^{\ddagger}$ & NA \\
\hline & $\begin{array}{l}\text { Lincoln \& } \\
\text { Flannaghan }{ }^{108}\end{array}$ & $\mathrm{RCT}$ & 123 & $\begin{array}{l}\text { DSM IV } \\
\text { Major } \\
\text { Minor }\end{array}$ & $\mathrm{BDI}$ & 16 & I & $29 \%$ & $13 \%$ \\
\hline
\end{tabular}

Notes: ${ }^{\dagger} P<0.005 ; \neq P<0.05 ; * P<0.05$, post-hoc exploratory analysis with significant placebo drop-out.

Abbreviations: RCT, double-blind randomized controlled trial; BDI, Beck Depression Inventory; DSM IV, Diagnostic and Statistical Manual of Mental Disorders, Fourth Edition; HADS, Hospital Anxiety and Depression Scale; HDRS, Hamilton Depression Rating Scale; MADRS, Montogomery-Asberg Depression Rating Scale; MES, Melancholia Scale; STAS, Spielberger Trait Anger Scale; ZSRDS, Zung Self Rating Depression Scale.

symptoms better than TCAs. ${ }^{97,98}$ However, given the unwanted side effects of TCAs, as outlined in the previous section, an SSRI should be considered first.

No medication is without potential adverse side effects. SSRIs are no exception. SSRI side effects include GI upset, diarrhea, insomnia (REM attenuation), headache, increased anxiety, sexual dysfunction, and increased suicidal ideation in young patients. Increased risk of bleeding resulting from inhibition of platelet aggregation caused by SSRIs is an important consideration for elderly stroke patients potentially on anticoagulation medications. Other adverse side effects include drug-drug interactions via cytochrome P450 inhibition. Fluvoxamine is a 'pan inhibitor' with significant effects on CYP1A2, CYP2C19, CYP2C9, CYP2D6, and CYP3A4. ${ }^{99}$ All SSRIs have some level of CYP2D6 inhibition, but fluoxetine and paroxetine are potent inhibitors of CYP2D6. Given the large number of medications metabolized at CYP2D6 and the frequency of polypharmacy in the elderly population, careful consideration of each addition or subtraction of medication is strongly suggested. Drug interactions can result in life-threatening toxicities or ineffective therapies despite being on a 'standard dose' of medication.

\section{Atypical antipsychotics}

Atypical antipsychotics are often used in the treatment of PSD patients to target symptoms such as mood lability and irritability. Although there are significant risks in long-term administration of this class of medications, short-term use may be helpful during the acute rehabilitation phase. Studies demonstrating the association between atypical antipsychotics and increased risk for stroke have been focused on elderly populations with prolonged antipsychotic use. All patients 
should be counseled on the risks of smoking and OCP use while on atypical antipsychotics as they may compound the risk of stroke. Providers should weigh the risks, benefits, alternatives, and precautions with both patients and caregivers prior to prescribing atypical antipsychotics in PSD patients.

\section{Mood stabilizers}

To our knowledge, there have been no human trials investigating the use of lithium or of other mood stabilizers in the treatment of PSD or related sequelae. Animal model studies, however, have indicated a limited role for the use of lithium in the treatment of mood lability and irritability following stroke. Yan et al. ${ }^{100}$ demonstrated that lithium reduces behavioral disturbances in rats poststroke and reported lithium as protective for ischemia-reperfusion injury resulting in improved grooming, spatial learning, and memory ability. ${ }^{58,100}$ Histologically, rats treated with lithium prior to CVA had decreased cell death in the hippocampal CA1 region. ${ }^{101}$ Other studies indicate that lithium may stimulate hippocampal neurogenesis via the extracellular signal-regulated kinase pathway. ${ }^{101}$

\section{Stimulant medications}

Stimulants have also shown some utility in the treatment of PSD and fatigue after stroke. Methylphenidate in particular has been shown to lower HAM-D scores in a randomized, controlled trial of PSD patients. ${ }^{102}$ Modafinil has shown efficacy in the treatment of poststroke fatigue, but research has yet to establish the optimal strategy for its use. ${ }^{103}$ Although the exact mechanism of action for modafinil is not entirely understood, it differs from the mechanism of action of amphetamines. Preclinical evidence suggests that modafinil decreases GABA activity in the area of the ascending reticular activating system thus promoting arousal. ${ }^{104}$ Modafinil lacks the peripheral sympathomimetic effects associated with methylphenidate use and is generally not associated with aggressive behavior. Stimulant medications have also been associated with increased ability to participate in physical therapy after a stroke. ${ }^{105}$ Despite the benefit of increased energy and decreased perceived disability, some stimulant medications such as methylphenidate carry a side effect profile that may actually worsen the patients' ability to participate in therapy. ${ }^{106}$ Side effects of stimulant medications include rare instances of mania, psychosis, suicidal ideation, depression, and stroke. Considerable caution should be exercised when weighing the risks and the benefits of stimulant use in poststroke patients as patients might be exquisitely sensitive to side effects of these medications. Given the increased sensitivity of this population, providers may consider initiating treatment at a low dose and slowly titrating increases in medication to target neurovegetative symptoms. Additionally, these medications should be used in a targeted and short-term fashion.

\section{Psychotherapy}

There is mixed evidence regarding the efficacy of CBT in PSD patients. Several studies have demonstrated the efficacy of CBT in the treatment of depression in adults and elderly patients. A study by Lincoln et al found CBT to improve mood in a small study of 19 stroke patients with depression. ${ }^{107}$ Likewise, a study of 41 elderly patients with disabilities, some with stroke $(n=18)$, demonstrated significant improvement in depressive symptoms with brief CBT group therapy. ${ }^{108}$ However, a randomized, controlled trial of CBT for the treatment of PSD in 123 patients did not find CBT to be efficacious. ${ }^{109}$ There were significant limitations to this recent randomized trial including a small sample size possibly lacking enough power to detect a significant difference between groups, shorter duration of treatment than previous studies, and no prescreening of patients into various treatment modalities. Patients were randomly assigned to treatment groups from a stroke register instead of being referred by a clinician for CBT based on the patients' wiliness and capacity to engage in the cognitive model. As with other therapies, it is difficult to fully assess the efficacy of CBT because of the heterogeneous nature of cognitive and motor deficits associated with strokes.

Other psychotherapy methods including problem-solving training and motivational interviewing have also been shown to improve mood after stroke but not specifically depressive symptoms in PSD. In a randomized, controlled trial of more than 400 patients, Watkins et al demonstrated an overall mood improvement on the general hospital questionnaire (GHQ-28). ${ }^{110}$ Motivational interviewing showed no improvement in the functional recovery of patients. In 2007, Robinson et al published research indicating that patients undergoing problem-solving therapy after stroke had a significantly lower incidence of depression over 12 months of treatment compared with placebo. However, this result was not statistically significant using an intention-to-treat analysis. ${ }^{111}$

\section{Conclusion}

Depression is a common psychiatric condition after stroke. Depression, like other psychiatric illnesses, compounds physical symptoms and contributes to increased morbidity, mortality, and poor rehabilitative outcomes. Providers should be committed to stroke prevention strategies including 
coordination with primary care providers regarding aggressive management of hypertension, diabetes, and other risk factors. For patients who have suffered a stroke, providers should regularly screen for symptoms of depression. Screenings should take a multifactorial approach given the heterogeneity of symptoms arising from a range of biopsychosocial factors. When treating PSD, it is recommended that providers carefully review the risks, benefits, and therapeutic alternatives with patients and their caregivers. Treatments should be tailored to the patients' symptom profile and their cognitive and physical deficits. Medications should be started slowly and titrated to the minimum dose needed to treat target symptoms of depression. Patients in this population are particularly sensitive to medication side effects and have increased risk of polypharmacy drug interactions while on multiple medications. Successful treatment of PSD symptoms improves treatment outcomes, enhances quality of life, and ultimately decreases morbidity and mortality in stroke patients.

\section{Disclosure}

The views expressed in this article are those of the authors and do not reflect the official policy or position of the Walter Reed Army Institute of Research, Walter Reed Army Medical Center, the Department of the Army, the Department of Defense, the US Government, or any of the institutions with which the authors are affiliated. This information was reviewed by the Walter Reed Army Medical Center and Walter Reed Army Institute of Research, and there is no objection to its presentation or publication.

\section{References}

1. World Health Organization. The World Health Report 2008. Geneva, Switzerland: WHO; 2008.

2. Castillo CS, Schultz SK, Robinson RG. Clinical correlates of early-onset and late-onset poststroke generalized anxiety. Am J Psychiatry. 1995; 152(8):1174-1179.

3. Chemerinski E, Levine SR. Neuropsychiatric disorders following vascular brain injury. Mt Sinai J Med. 2006;73(7):1006-1014.

4. Morris PL, Robinson RG, Raphael B. Prevalence and course of depressive disorders in hospitalized stroke patients. Int $J$ Psychiatry Med. 1990;20(4):349-364.

5. Gordon WA, Hibbard MR. Poststroke depression: an examination of the literature. Arch Phys Med Rehabil. 1997;78(6):658-663.

6. Hosking SG, Marsh NV, Friedman PJ. Poststroke depression: prevalence, course, and associated factors. Neuropsychol Rev. 1996;6(3): 107-133.

7. Spencer KA, Tompkins CA, Schulz R. Assessment of depression in patients with brain pathology: the case of stroke. Psychol Bull. 1997; 122(2):132-152.

8. Carota A, Berney A, Aybek S, et al. A prospective study of predictors of poststroke depression. Neurology. 2005;64(3):428-433.

9. Lenze EJ, Rogers JC, Martire LM, et al. The association of late-life depression and anxiety with physical disability: a review of the literature and prospectus for future research. Am J Geriatr Psychiatry. 2001;9(2): $113-135$.
10. Schwartz JA, Speed NM, Brunberg JA, Brewer TL, Brown M, Greden JF. Depression in stroke rehabilitation. Biol Psychiatry. 1993; 33(10):694-699.

11. Herrmann N, Black SE, Lawrence J, Szekely C, Szalai JP. The Sunnybrook stroke study: a prospective study of depressive symptoms and functional outcome. Stroke. 1998;29(3):618-624.

12. Ramasubbu R, Robinson RG, Flint AJ, Kosier T, Price TR. Functional impairment associated with acute poststroke depression: the stroke data bank study. J Neuropsychiatry Clin Neurosci. 1998;10(1):26-33.

13. Austin MP, Mitchell P, Goodwin GM. Cognitive deficits in depression: possible implications for functional neuropathology. Br J Psychiatry. 2001;178:200-206.

14. Kauhanen M, Korpelainen JT, Hiltunen P, et al. Poststroke depression correlates with cognitive impairment and neurological deficits. Stroke. 1999;30(9):1875-1880.

15. Schulz R, Beach SR, Ives DG, Martire LM, Ariyo AA, Kop WJ. Association between depression and mortality in older adults: the cardiovascular health study. Arch Intern Med. 2000;160(12):1761-1768.

16. Morris PL, Robinson RG, Andrzejewski P, Samuels J, Price TR. Association of depression with 10 -year poststroke mortality. Am J Psychiatry. 1993;150(1):124-129.

17. Williams LS, Ghose SS, Swindle RW. Depression and other mental health diagnoses increase mortality risk after ischemic stroke. $\mathrm{Am} J$ Psychiatry. 2004;161(6):1090-1095.

18. Gillen R, Tennen H, McKee TE, Gernert-Dott P, Affleck G. Depressive symptoms and history of depression predict rehabilitation efficiency in stroke patients. Arch Phys Med Rehabil. 2001;82(12):1645-1649.

19. Ghose SS, Williams LS, Swindle RW. Depression and other mental health diagnoses after stroke increase inpatient and outpatient medical utilization three years poststroke. Med Care. 2005;43(12):1259-1264.

20. Jia H, Damush TM, Qin H, et al. The impact of poststroke depression on healthcare use by veterans with acute stroke. Stroke. 2006;37(11): 2796-2801.

21. Gillen R, Eberhardt TL, Tennen H, Affleck G, Groszmann Y. Screening for depression in stroke: relationship to rehabilitation efficiency. J Stroke Cerebrovasc Dis. 1999;8(5):300-306.

22. Dennis M, O’Rourke S, Lewis S, Sharpe M, Warlow C. A quantitative study of the emotional outcome of people caring for stroke survivors. Stroke. 1998;29(9):1867-1872.

23. Anderson CS, Linto J, Stewart-Wynne EG. A population-based assessment of the impact and burden of caregiving for long-term stroke survivors. Stroke. 1995;26(5):843-849.

24. Scholte op Reimer WJ, de Haan RJ, Rijnders PT, Limburg M, van den Bos GA. The burden of caregiving in partners of long-term stroke survivors. Stroke. 1998;29(8):1605-1611.

25. Fedoroff JP, Starkstein SE, Parikh RM, Price TR, Robinson RG. Are depressive symptoms nonspecific in patients with acute stroke? Am J Psychiatry. 1991;148(9):1172-1176.

26. Rusin MJ. Stroke rehabilitation: a geropsychological perspective. Arch Phys Med Rehabil. 1990;71(11):914-922.

27. Cohen-Cole SA, Stoudemire A. Major depression and physical illness. Special considerations in diagnosis and biologic treatment. Psychiatr Clin North Am. 1987;10(1):1-17.

28. Rifkin A, Reardon G, Siris S, et al. Trimipramine in physical illness with depression. J Clin Psychiatry. 1985;46(2 Pt 2):4-8.

29. Rapp SR, Vrana S. Substituting nonsomatic for somatic symptoms in the diagnosis of depression in elderly male medical patients. $\mathrm{Am} \mathrm{J}$ Psychiatry. 1989;146(9):1197-1200.

30. Endicott J. Measurement of depression in patients with cancer. Cancer. 1984;53 Suppl 10:2243-2249.

31. Bukberg J, Penman D, Holland JC. Depression in hospitalized cancer patients. Psychosom Med. 1984;46(3):199-212.

32. Alexopoulos GS, Meyers BS, Young RC, Kakuma T, Silbersweig D, Charlson M. Clinically defined vascular depression. Am J Psychiatry. 1997;154(4):562-565.

33. Rabkin JG, Charles E, Kass F. Hypertension and DSM-III depression in psychiatric outpatients. Am J Psychiatry. 1983;140(8):1072-1074. 
34. Carney RM, Rich MW, Tevelde A, Saini J, Clark K, Jaffe AS. Major depressive disorder in coronary artery disease. Am JCardiol. 1987;60(16): $1273-1275$.

35. Robinson RG, Morris PL, Fedoroff JP. Depression and cerebrovascular disease. J Clin Psychiatry. 1990;51(Suppl):26-31; discussion 32-33.

36. Lipsey JR, Spencer WC, Rabins PV, Robinson RG. Phenomenological comparison of poststroke depression and functional depression. Am J Psychiatry. 1986;143(4):527-529.

37. Robinson RG, Kubos KL, Starr LB, Rao K, Price TR. Mood disorders in stroke patients. Importance of location of lesion. Brain. 1984;107(Pt 1): 81-93.

38. Fujikawa T, Yamawaki S, Touhouda Y. Incidence of silent cerebral infarction in patients with major depression. Stroke. 1993;24(11): 1631-1634.

39. Coffey CE, Figiel GS, Djang WT, Weiner RD. Subcortical hyperintensity on magnetic resonance imaging: a comparison of normal and depressed elderly subjects. Am J Psychiatry. 1990;147(2):187-189.

40. Krishnan KR, Goli V, Ellinwood EH, France RD, Blazer DG, Nemeroff CB. Leukoencephalopathy in patients diagnosed as major depressive. Biol Psychiatry. 1988;23(5):519-522.

41. Figiel GS, Krishnan KR, Doraiswamy PM, Rao VP, Nemeroff CB, Boyko OB. Subcortical hyperintensities on brain magnetic resonance imaging: a comparison between late age onset and early onset elderly depressed subjects. Neurobiol Aging. 1991;12(3):245-247.

42. Fujikawa T, Yamawaki S, Touhouda Y. Background factors and clinical symptoms of major depression with silent cerebral infarction. Stroke. 1994;25(4):798-801.

43. Folstein MF, Maiberger R, McHugh PR. Mood disorder as a specific complication of stroke. J Neurol Neurosurg Psychiatry. 1977;40(10): 1018-1020.

44. Robinson RG, Shoemaker WJ, Schlumpf M, Valk T, Bloom FE. Effect of experimental cerebral infarction in rat brain on catecholamines and behaviour. Nature. 1975;255(5502):332-334.

45. Beblo T, Wallesch CW, Herrmann M. The crucial role of frontostriatal circuits for depressive disorders in the postacute stage after stroke. Neuropsychiatry Neuropsychol Behav Neurol. 1999;12(4): 236-246.

46. Robinson RG, Starr LB, Lipsey JR, Rao K, Price TR. A two-year longitudinal study of post-stroke mood disorders: dynamic changes in associated variables over the first six months of follow-up. Stroke. 1984;15(3):510-517.

47. Starkstein SE, Robinson RG, Berthier ML, Parikh RM, Price TR. Differential mood changes following basal ganglia vs thalamic lesions. Arch Neurol. 1988;45(7):725-730.

48. Robinson RG. Vascular depression and poststroke depression: where do we go from here? Am J Geriatr Psychiatry. 2005;13(2):85-87.

49. Dieguez S, Staub F, Bruggimann L, Bogousslavsky J. Is poststroke depression a vascular depression? J Neurol Sci. 2004;226(1-2):53-58.

50. Robins AH. Are stroke patients more depressed than other disabled subjects? J Chronic Dis. 1976;29(7):479-482.

51. Starkstein SE, Berthier ML, Fedoroff P, Price TR, Robinson RG. Anosognosia and major depression in 2 patients with cerebrovascular lesions. Neurology. 1990;40(9):1380-1382.

52. Starkstein SE, Fedoroff JP, Price TR, Leiguarda R, Robinson RG. Anosognosia in patients with cerebrovascular lesions. A study of causative factors. Stroke. 1992;23(10):1446-1453.

53. Carson AJ, MacHale S, Allen K, et al. Depression after stroke and lesion location: a systematic review. Lancet. 2000;356(9224):122-126.

54. Bozikas VP, Gold G, Kovari E, et al. Pathological correlates of poststroke depression in elderly patients. Am J Geriatr Psychiatry. 2005; 13(2):166-169.

55. Burvill PW, Johnson GA, Jamrozik KD, Anderson CS, StewartWynne EG, Chakera TM. Prevalence of depression after stroke: the Perth community stroke study. Br J Psychiatry. 1995;166(3):320-327.

56. Kendler KS, Kessler RC, Neale MC, Heath AC, Eaves LJ. The prediction of major depression in women: toward an integrated etiologic model. Am J Psychiatry. 1993;150(8):1139-1148.
57. Sharpe M, Hawton K, Seagroatt V, et al. Depressive disorders in long-term survivors of stroke. Associations with demographic and social factors, functional status, and brain lesion volume. Br J Psychiatry. 1994; 164(3):380-386

58. Whyte EM, Mulsant BH. Post stroke depression: epidemiology, pathophysiology, and biological treatment. Biol Psychiatry. 2002;52(3): 253-264.

59. Andersen G, Vestergaard K, Ingemann-Nielsen M, LauritzenL. Risk factors for post-stroke depression. Acta Psychiatr Scand. 1995;92(3):193-198.

60. Berg A, Palomaki H, Lehtihalmes M, Lonnqvist J, Kaste M. Poststroke depression in acute phase after stroke. Cerebrovasc Dis. 2001;12(1): 14-20.

61. Singh A, Black SE, Herrmann N, et al. Functional and neuroanatomic correlations in poststroke depression: the Sunnybrook stroke study. Stroke. 2000;31(3):637-644.

62. Gonzalez-Torrecillas JL, Mendlewicz J, Lobo A. Effects of early treatment of poststroke depression on neuropsychological rehabilitation. Int Psychogeriatr. 1995;7(4):547-560.

63. Morris PL, Robinson RG, Raphael B, Samuels J, Molloy P. The relationship between risk factors for affective disorder and poststroke depression in hospitalised stroke patients. Aust N Z J Psychiatry. 1992;26(2): 208-217.

64. Paradiso S, Robinson RG. Gender differences in poststroke depression. J Neuropsychiatry Clin Neurosci. 1998;10(1):41-47.

65. Starkstein SE, Robinson RG, Price TR. Comparison of patients with and without poststroke major depression matched for size and location of lesion. Arch Gen Psychiatry. 1988;45(3):247-252.

66. Morris PL, Robinson RG. Personality neuroticism and depression after stroke. Int J Psychiatry Med. 1995;25(1):93-102.

67. Starkstein SE, Robinson RG, Honig MA, Parikh RM, Joselyn J, Price TR. Mood changes after right-hemisphere lesions. Br J Psychiatry. 1989;155:79-85

68. Lewis A, Segal A. Hyperlipidemia and primary prevention of stroke: does risk factor identification and reduction really work? Curr Atheroscler Rep. 2010;12(4):225-229.

69. Writing Group Members, Lloyd-Jones D, Adams RJ, et al. Heart disease and stroke statistics-2010 update: a report from the American Heart Association. Circulation. 2010;121(7):e46-e215.

70. Hackett ML, Anderson CS, House A, Halteh C. Interventions for preventing depression after stroke. Cochrane Database Syst Rev. 2008; 3:CD003689.

71. Rasmussen A, Lunde M, Poulsen DL, Sorensen K, Qvitzau S, Bech P. A double-blind, placebo-controlled study of sertraline in the prevention of depression in stroke patients. Psychosomatics. 2003;44(3):216-221.

72. Desmond DW, Remien RH, Moroney JT, Stern Y, Sano M, Williams JB. Ischemic stroke and depression. J Int Neuropsychol Soc. 2003;9(3): 429-439.

73. Tang WK, Chan SS, Chiu HF, et al. Poststroke depression in Chinese patients: frequency, psychosocial, clinical, and radiological determinants. J Geriatr Psychiatry Neurol. 2005;18(1):45-51.

74. Burvill P, Johnson G, Jamrozik K, Anderson C, Stewart-Wynne E. Risk factors for post-stroke depression. Int J Geriatr Psychiatry. 1997;12(2): 219-226.

75. Astrom M, Adolfsson R, Asplund K. Major depression in stroke patients. A 3-year longitudinal study. Stroke. 1993;24(7):976-982.

76. Gainotti G, Azzoni A, Razzano C, Lanzillotta M, Marra C, Gasparini F. The post-stroke depression rating scale: a test specifically devised to investigate affective disorders of stroke patients. J Clin Exp Neuropsychol. 1997;19(3):340-356

77. Gainotti G, Azzoni A, Marra C. Frequency, phenomenology and anatomical-clinical correlates of major post-stroke depression. Br J Psychiatry. 1999;175:163-167.

78. Aben I, Verhey F, Lousberg R, Lodder J, Honig A. Validity of the beck depression inventory, hospital anxiety and depression scale, SCL-90, and hamilton depression rating scale as screening instruments for depression in stroke patients. Psychosomatics. 2002;43(5) 386-393. 
79. Healey AK, Kneebone II, Carroll M, Anderson SJ. A preliminary investigation of the reliability and validity of the brief assessment schedule depression cards and the beck depression inventory-fast screen to screen for depression in older stroke survivors. Int J Geriatr Psychiatry. 2008;23(5):531-536.

80. Bennett HE, Thomas SA, Austen R, Morris AM, Lincoln NB. Validation of screening measures for assessing mood in stroke patients. Br J Clin Psychol. 2006;45(Pt 3):367-376.

81. Post F. Significance of Affective Symptoms in Old Age. Maudsley Monograph. London, UK: Oxford University Press; 1962:10.

82. Wade DT, Legh-Smith J, Hewer RA. Depressed mood after stroke. A community study of its frequency. Br J Psychiatry. 1987;151: 200-205.

83. Robinson RG, Starr LB, Lipsey JR, Rao K, Price TR. A two-year longitudinal study of poststroke mood disorders. In-hospital prognostic factors associated with six-month outcome. J Nerv Ment Dis. 1985; 173(4):221-226

84. Andersen G, Vestergaard K, Lauritzen L. Effective treatment of poststroke depression with the selective serotonin reuptake inhibitor citalopram. Stroke. 1994;25(6):1099-1104.

85. House A, Dennis M, Hawton K, Warlow C. Methods of identifying mood disorders in stroke patients: experience in the Oxfordshire community stroke project. Age Ageing. 1989;18(6):371-379.

86. Douglas IJ, Smeeth L. Exposure to antipsychotics and risk of stroke: self controlled case series study. BMJ. 2008;337:a1227. Doi: 10.1136/ bmj.a1227.

87. Rayner L, Price A, Evans A, Valsraj K, Higginson IJ, Hotopf M. Antidepressants for depression in physically ill people. Cochrane Database Syst Rev. 2010;3:CD007503.

88. Gainotti G, Antonucci G, Marra C, Paolucci S. Relation between depression after stroke, antidepressant therapy, and functional recovery. J Neurol Neurosurg Psychiatry. 2001;71(2):258-261.

89. Robinson RG, Schultz SK, Castillo C, et al. Nortriptyline versus fluoxetine in the treatment of depression and in short-term recovery after stroke: a placebo-controlled, double-blind study. Am J Psychiatry. 2000;157(3):351-359.

90. Lipsey JR, Robinson RG, Pearlson GD, Rao K, Price TR. Nortriptyline treatment of post-stroke depression: a double-blind study. Lancet. 1984;1(8372):297-300.

91. Murray V, von Arbin M, Bartfai A, et al. Double-blind comparison of sertraline and placebo in stroke patients with minor depression and less severe major depression. J Clin Psychiatry. 2005;66(6):708-716.

92. Fruehwald S, Gatterbauer E, Rehak P, Baumhackl U. Early fluoxetine treatment of post-stroke depression-a three-month double-blind placebo-controlled study with an open-label long-term follow up. J Neurol. 2003;250(3):347-351.

93. Choi-Kwon S, Han SW, Kwon SU, Kang DW, Choi JM, Kim JS. Fluoxetine treatment in poststroke depression, emotional incontinence, and anger proneness: a double-blind, placebo-controlled study. Stroke. 2006;37(1):156-161.

94. Reding MJ, Orto LA, Winter SW, Fortuna IM, di Ponte P, McDowell FH. Antidepressant therapy after stroke. A double-blind trial. Arch Neurol. 1986;43(8):763-765.

95. Jorge RE, Robinson RG, Arndt S, Starkstein S. Mortality and poststroke depression: a placebo-controlled trial of antidepressants $\mathrm{Am} \mathrm{J}$ Psychiatry. 2003;160(10):1823-1829.

Psychology Research and Behavior Management

\section{Publish your work in this journal}

Psychology Research and Behavior Management is an international, peerreviewed, open access journal focusing on the science of psychology and its application in behavior management to develop improved outcomes in the clinical, educational, sports and business arenas. Specific topics covered include: Neuroscience, memory \& decision making; Behavior
96. Rampello L, Chiechio S, Nicoletti G, et al. Prediction of the response to citalopram and reboxetine in post-stroke depressed patients. Psychopharmacology (Berl). 2004;173(1-2):73-78.

97. Turner-Stokes L, Hassan N. Depression after stroke: a review of the evidence base to inform the development of an integrated care pathway. Part 2: Treatment alternatives. Clin Rehabil. 2002;16(3):248-260.

98. Lindsay P, Bayley M, Hellings C, Hill M, Woodbury E, Phillips S. Selected topics in stroke management. Identification and management of post-stroke depression. In: Canadian best practice recommendations for stroke care. CMAJ. 2008;179 Suppl 12:E65-E67.

99. Hemeryck A, Belpaire FM. Selective serotonin reuptake inhibitors and cytochrome P-450 mediated drug-drug interactions: an update. Curr Drug Metab. 2002;3(1):13-37.

100. Yan XB, Wang SS, Hou HL, Ji R, Zhou JN. Lithium improves the behavioral disorder in rats subjected to transient global cerebral ischemia. Behav Brain Res. 2007;177:282-289.

101. Yan XB, Hou HL, Wu LM, Liu J, Zhou JN. Lithium regulates hippocampal neurogenesis by ERK pathway and facilitates recovery of spatial learning and memory in rats after transient global cerebral ischemia. Neuropharmacology. 2007;53:487-495.

102. Grade C, Redford B, Chrostowski J, Toussaint L, Blackwell B. Methylphenidate in early poststroke recovery: a double-blind, placebocontrolled study. Arch Phys Med Rehabil. 1998;79(9):1047-1050.

103. Annoni JM, Staub F, Bogousslavsky J, Brioschi A. Frequency, characterisation and therapies of fatigue after stroke. Neurol Sci. 2008; 29 Suppl 2:S244-S246.

104. Qureshi A, Lee-Chiong T Jr. Medications and their effects on sleep. Med Clin North Am. 2004;88(3):751-766, x.

105. Walker-Batson D, Smith P, Curtis S, Unwin H, Greenlee R. Amphetamine paired with physical therapy accelerates motor recovery after stroke. Further evidence. Stroke. 1995;26(12):2254-2259.

106. Lazarus LW, Winemiller DR, Lingam VR, et al. Efficacy and side effects of methylphenidate for poststroke depression. J Clin Psychiatry. 1992;53(12):447-449.

107. Lincoln NB, Flannaghan T, Sutcliffe L, Rother L. Evaluation of cognitive behavioural treatment for depression after stroke: a pilot study. Clin Rehabil. 1997;11(2):114-122.

108. Kemp BJ, Corgait M, Gill C. Effects of brief cognitive behavioral group psychotherapy on older persons with and without disabling illness. Behav Health Ageing. 1992;2:21-28.

109. Lincoln NB, Flannaghan T. Cognitive behavioral psychotherapy for depression following stroke: a randomized controlled trial. Stroke. 2003;34(1):111-115.

110. Watkins CL, Auton MF, Deans CF, et al. Motivational interviewing early after acute stroke: a randomized, controlled trial. Stroke. 2007; 38(3):1004-1009.

111. Robinson RG, Jorge RE, Moser DJ, et al. Escitalopram and problemsolving therapy for prevention of poststroke depression: a randomized controlled trial. JAMA. 2008;299(20):2391-2400.

112. Wiart L, Petit H, Joseph PA, Mazaux JM, Barat M. Fluoxetine in early poststroke depression: A double-blind placebo-controlled study. Stroke. 2000;31:1829-1832.

modification \& management; Clinical applications; Business \& sports performance management; Social and developmental studies; Animal studies. The manuscript management system is completely online and includes a quick and fair peer-review system. Visit http://www.dovepress. com/testimonials.php to read real quotes from published authors. 